\title{
УДК 622.831:622.274
}

\section{ГЕОМЕХАНИЧЕСКОЕ ОБОСНОВАНИЕ ПАРАМЕТРОВ УСТОЙЧИВЫХ КАМЕР И ЦЕЛИКОВ В СЛОЖНЫХ ГОРНО-ГЕОЛОГИЧЕСКИХ УСЛОВИЯХ}

\author{
Харисов Тимур Фаритович', \\ timur-ne@mail.ru \\ Харисова Ольга Дмитриевна', \\ OlgaZheltysheva@gmail.com \\ Институт горного дела УрО РАН, \\ Россия, 620075, г. Екатеринбург, ул. Мамина-Сибиряка, 58.
}

Актуальность исследования обусловлена необходимостью обеспечения безопасности на Соколовском подземном руднике, а также повышения полноты и качества выемки руды в сложных горно-геологических условиях - при наличии покрывающей толщи обводненных рыхлых отложений.

Цель: определить оптимальные параметры устойчивых камер и целиков для предотвращения обрушения горных пород и проникновения песчано-глинистых масс в подземные выработки.

Объект: массив горных пород на Северном участке Соколовского месторождения

Методы. Многовариантное численное моделирование методом конечных элементов в двумерной постановке выполнялось в программе Rocscience RS2, что позволило учесть большое количество факторов, влияющих на состояние массива. При расчетах приняты во внимание не только физико-механические свойства пород и действующие в массиве напряжения, но и структурные характеристики массива, а также степень техногенного воздействия. В качестве модели поведения массива использовалась модель Хоека-Брауна, отличительным преимуществом которой является ее нелинейность. Так как реальный массив характеризуется неоднородностью прочностных свойств и напряженно-деформированного состояния, был выполнен предусмотренный в программном комплексе Rocscience вероятностный анализ, учитывающий изменение граничных условий в установленных интервалах для создаваемой модели.

В результате численного моделирования определено изменение напряженно-деформированного состояния массива, на основании чего вычислены коэффициент устойчивости окружающего массива, величины и направления его смещений, а также установлены зоны распределения вероятности разрушения массива в заданных интервалах граничных условий. Определены параметры камер и целиков, обеспечивающие общую устойчивость, минимизирующие возможность прорыва водогрязевых масс в выработки.

Выводы. Сохранение устойчивости кровли подземных камер при отработке очистных рудных блоков на шахте "Соколовская» позволит снизить риск проникновения песчано-глинистых масс в подземные выработки, обеспечивая безопасное и эффективное ведение горных работ, а также повысить полноту и качество выемки руды. Выполненное методом конечных элементов многовариантное численное моделирование влияния очистных выработок на массив позволило определить оптимальные геометрические параметры камер и целиков, обеспечивающие устойчивость окружающего массива. Применение программного комплекса Rocscience RS2 в результате учета большого количества факторов, влияющих на состояние массива, значительно повышает надежность оценки устойчивости массива.

\section{Ключевые слова:}

Подземная разработка, параметры камер и целиков, устойчивость выработок, обрушение горных пород, напряженно-деформированное состояние, модель Хоека-Брауна, метод конечных элементов, численное моделирование, Rocscience RS2, конвергенция выработок.

\section{Введение}

Одной из основных задач в горной науке является обеспечение безопасности ведения горных работ при одновременном поддержании эффективности и рентабельности разработки. Особенно данная проблема актуальна для месторождений, находящихся в сложных горно-геологических условиях.

Разработка Северного участка Соколовского месторождения, на котором в настоящее время производится добыча железной руды подземным способом, осложняется неблагоприятной геомеханической ситуацией на подземном руднике. Главным негативным природным фактором, затрудняющим эффективное и безопасное ведение горных работ, является наличие толщи обводненных рыхлых мезокайнозойских отложений, перекрывающей скальную рудоносную зону месторождения и создающей опасность прорыва водогрязевых масс в горные выработки.
На первом этапе работы рудника применялась этажно-камерная система разработки с закладкой выработанного пространства твердеющими смесями, однако и в этих условиях имели место обрушения вмещающих пород, в некоторых случаях - с выходом на дневную поверхность. Сразу же после образования воронок обрушения в них начинался приток подземных вод из олигоценового горизонта, и они заполнялись водой до статического уровня на данном горизонте. Все образовавшиеся на поверхности воронки засыпались скальной породой для предотвращения оплывания их стенок и снижения объема свободной воды.

После 1998 г. на руднике произошел переход на систему разработки с обрушением руды и вмещающих пород. В результате проведения добычных работ на шахтном поле образовалось более 30 воронок обрушения, при этом их засыпка не производилась. Суммарный объем поверхностных 
вод, накопившихся во всех открытых воронках, к 2005 г. составил несколько сотен тысяч м ${ }^{3}$. Тем не менее, до 2005 г. аварийных прорывов воды не происходило, но периодически наблюдались выходы в горные выработки глинисто-песчаных или песчано-глинистых масс с обломками скальных пород.

При дальнейшем развитии горных работ начали появляться вторичные воронки обрушения, образовывавшиеся в старых воронках, заполненных поверхностными водами. Три таких повторных выхода сопровождались кратковременными прорывами поверхностных вод в подземные горные выработки, причем последний - наиболее крупный - имел катастрофические последствия.

Для предотвращения в будущем прорывов поверхностных вод была произведена засыпка всех открытых воронок скальными породами, а на территории зоны обрушения образован отвал из пород, извлеченных из Соколовского карьера [1]. После внедрения этих мер прорывов воды больше не происходило. Однако в настоящее время практически во всех отработанных и отрабатываемых панелях отмечены случаи выхода песчано-глинистых масс (далее - ПГМ) на горизонты выпуска - в дучки и доставочные выработки. Их выход влечет за собой не только засорение руды, но и при больших объемах вышедших ПГМ может приводить к закупориванию дучек и проникновению масс в подготовительно-нарезные выработки, вплоть до полной остановки работ.

В результате в недоступных более блоках остаются огромные потери руды, а также возрастает объем дополнительных подготовительно-нарезных работ, необходимых для доступа к оставшимся частям рудного блока.

Для снижения рисков проникновения ПГМ в выработки было предложено перейти от одностадийной технологии отработки очистных рудных блоков - системы этажного принудительного обрушения со сплошной выемкой руды под обрушенными породами, используемой в настоящее время на руднике, на двухстадийную технологию - систему разработки этажным принудительным обрушением с вертикальными компенсационными камерами. При данной системе первоначально часть запасов блока вынимают в виде камер, а затем на образовавшееся компенсационное пространство обрушают оставшуюся часть блока путем разрушения межкамерных и межблочных целиков. Затем осуществляют донный выпуск взорванной руды под налегающими обрушенными породами.

Главным преимуществом данной системы разработки является возможность выемки большего процента чистой руды из камер, чем под обрушенными породами. Недостатком данной системы является наличие риска возникновения внезапного и неконтролируемого самообрушения компенсационных камер, что чревато нарушениями остального массива и опасностью воздушных ударов. Однако высокая трещиноватость и сравнительно низ- кая устойчивость рудного массива Соколовского рудника уменьшает вероятность возникновения воздушных ударов, поскольку возможные самообрушения в камерах с большой вероятностью будут развиваться постепенно: с вывалами более мелких породных блоков, чем в низкотрещиноватых массивах. При этом участок возникновения самообрушения в камере можно использовать в качестве индикатора местоположения возможного прорыва ПГМ.

\section{Объект и методы исследований}

Северный участок, как и все Соколовское месторождение в целом, сложен двумя комплексами горных пород: палеозойским, представленным сложно дислоцированными эффузивно-осадочными породами нижнего карбона, и вышележащим мезокайнозойским. Верхний комплекс пород сложен горизонтально залегающими осадочными породами, представленными песчано-глинистыми отложениями мезокайнозойского возраста, средней мощностью 115 м. Наличие данной водоносной песчано-глинистой толщи, перекрывающей скальную рудоносную зону месторождения, и является главным негативным природным фактором, затрудняющим эффективное и безопасное ведение горных работ.

Отрабатываемый в настоящее время рудный блок на Северном участке месторождения представлен двумя рудными линзами 3а и $3 б$, разделенными прослоем мощностью от 5 до 35 м. Мощность основной рудной линзы $3 б$ увеличивается по падению от $10-15$ м на горизонте -120 до $30-50$ м на горизонте -190 м. Падение залежи крутое, угол 70-85. Рудное тело сложено вкрапленными и полосчатыми рудами гранат-пироксен-магнетитового состава. Рудная линза За является маломощной (4-8 м), невыдержанной по падению. На горизонтах -260 и -340 м общие размеры рудной пачки по простиранию - 1500 м, по падению - до 140 м.

Категория устойчивости руд IV-V, коэффициент крепости по шкале проф. М.M. Протодьяконова $-f=5-8$. С глубины 300 м (от земной поверхности) месторождение отнесено к категории склонных к горным ударам. В настоящее время горные работы на исследуемом участке достигли горизонта -260 м, что при абсолютных отметках поверхности около 190 м соответствует глубине 450 м.

Для установления оптимальных параметров камер, при которых их кровля будет сохранять общую устойчивость, а также межкамерных и межблочных целиков по простиранию и вкрест простирания, было выполнено компьютерное моделирование методом конечных элементов в двумерной постановке. Использование метода численного моделирования позволяет учитывать гораздо большее количество факторов, влияющих на состояние массива [2-7]. Данный метод находит все более широкое применение для расчета устойчивости подземных выработок, способствуя решению целого ряда задач - снижения потерь и разубоживания 


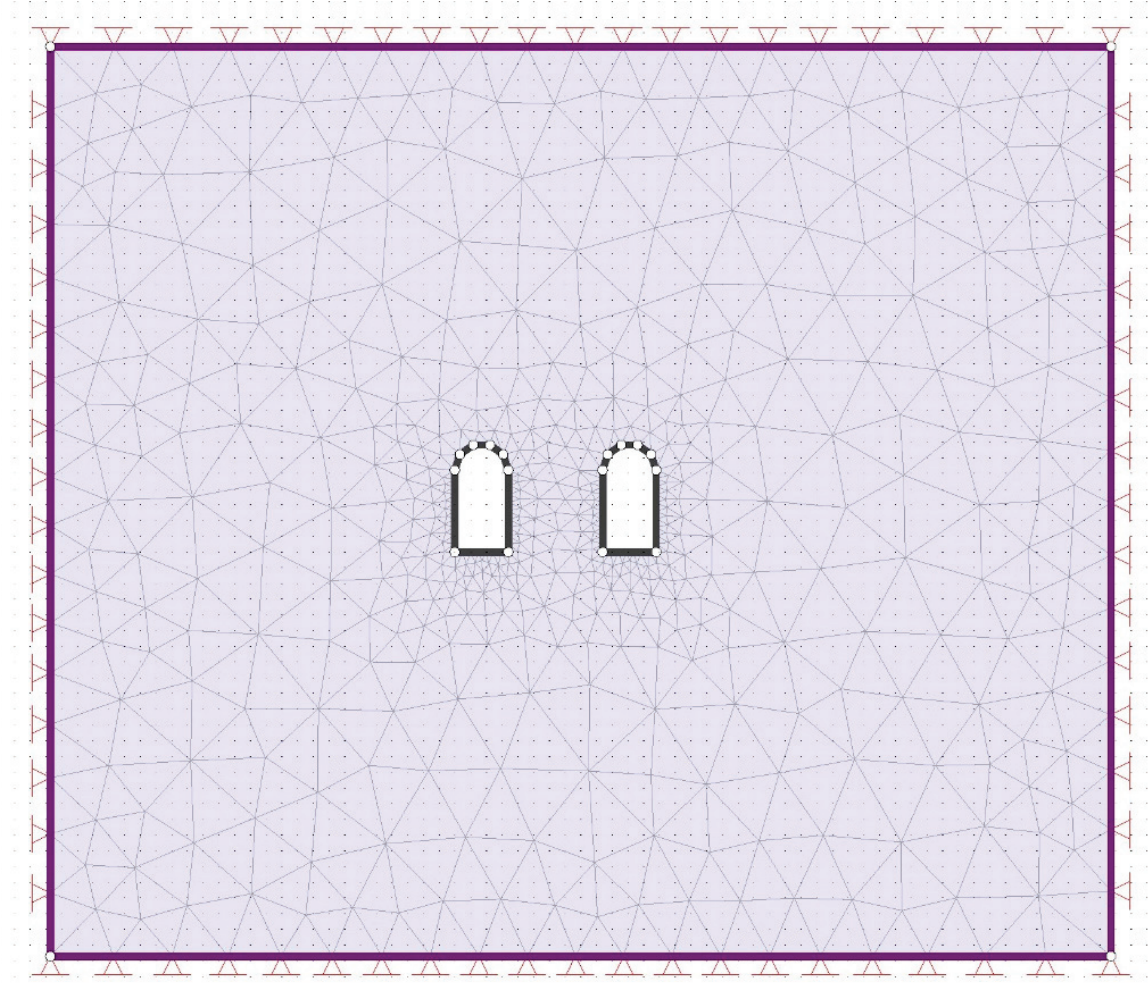

Рис. 1. Конечно-элементная модель массива горных пород, вмещающего подземные выработки (калеры)

Fig. 1. Finite element model of rock mass including underground excavations (chambers)

руды [8-10], обеспечения безопасности горных работ в удароопасных условиях [3, 11], совершенствования систем разработки [12-18] и др.

Моделирование выполнялось в программном комплексе Rocscience RS2 (ранее - Phase2) [19]. Программа RS2 представляет собой мощный инструмент для моделирования методом конечных элементов, позволяя быстро создавать сложные многостадийные модели, а также предоставляет широкие возможности для всестороннего анализа полученных результатов [12, 20].

Созданная модель представляет собой упругопластичный массив, в котором поочередно были образованы две выработки (камеры), разделенные междду собой целиком (рис. 1). Выбор количества камер обоснован размерами очистного блока на участке работ.

Граничные условия для модели установлены по данным ранее выполненных лабораторных испытаний образцов: $\gamma=0,026 \mathrm{MH} / \mathrm{m}^{3}-$ удельный вес горного массива (налегающей породной толщи); $\lambda=\mu /(1-\mu)=0,3 /(1-0,3)=0,4-$ коэффициент бокового давления горного массива; $\mu=0,3-$ коэффициент Пуассона.

В модели заданы действующие в массиве горизонтальные $\left(\sigma_{\text {шир }}, \sigma_{\text {мер }}\right)$ и вертикальные напряжения $\left(\sigma_{\text {верт }}\right)$, определенные ранее натурными измерениями на данном участке месторождения [21, 22]: $\sigma_{\text {верт }}=13 \mathrm{MПа,} \sigma_{\text {шир }}=16 \mathrm{MПа,} \sigma_{\text {мер }}=16-20$ Мпа.

Моделирование производилось для глубины $H=500$ м.
Так как основной задачей данного исследования является оценка устойчивости рудных целиков, в качестве прочностных характеристик пород массива были приняты физико-механические свойства магнетитовой руды, определенные ранее лабораторными испытаниями в рамках разработки проекта на отработку данного участка месторождения:

- Предел прочности образца пород на сжатие $\sigma_{\mathrm{cm}}=45 \mathrm{M \Pi а}$

- Модуль Юнга $E=5300$ МПа.

В качестве модели поведения массива использовалась модель Хоека-Брауна (Hoek-Brown) [23, $24]$, одним из главных достоинств которой, в отличии от наиболее распространенной на практике модели Мора-Кулона, является ее нелинейность. Эмпирические параметры, предложенные Э. Хоеком и Э.Т. Брауном, учитывающие разнообразные структурные особенности и свойства скальных грунтов, были получены ими при анализе множества лабораторных и полевых испытаний [25].

Одной из самых важных характеристик грунта при использовании модели Хоека-Брауна является геологический индекс прочности GSI - безразмерная величина, характеризующая трещиноватость и раздробленность горных пород [25]. Данный параметр определяется на основании визуальной оценки структуры массива и поверхности трещин.

Помимо возможности учета структурных характеристик массива горных пород, модель также 
принимает во внимание степень техногенного влияния на массив, зависящую от способов ведения горных работ. Коэффициент нарушения $D$ характеризует вызываемое техногенным воздействием дополнительное нарушение сплошности массива. Данный параметр не зависит от типа, строения и физико-механических свойств исследуемого массива и не требует каких-либо дополнительных исследований - достаточно лишь сведений о способе отработки месторождения [25].

Параметр ненарушенной породы $m_{i}$ устанавливается на основе геологического описания горной породы в соответствии с ее литологическим типом. Этот параметр также был получен Э. Хоеком и Э.Т. Брауном эмпирическим путем; он никак не описывает степень трещиноватости или физико-механические свойства грунта, а лишь соответствует его литологии и генезису [25].

Вышеперечисленные эмпирические параметры, использующиеся в модели Хоека-Брауна, определяются по соответствующим таблицам и диаграммам, представленным в работах авторов данной модели [23, 24], а также заложенным в программное обеспечение [19].

Так как массив характеризуется неоднородностью прочностных свойств и напряженно-деформированного состояния, то в программном комплексе Rocscience предусмотрен вероятностный анализ, учитывающий изменение в установленных интервалах заданных граничных условий для создаваемой модели массива (табл. 1).

Таблица 1. Интервалы изменения граничных условий

Table 1. Boundary conditions variation intervals

\begin{tabular}{|c|c|c|}
\hline $\begin{array}{l}\text { Свойства массива } \\
\text { Rock mass properties }\end{array}$ & $\begin{array}{c}\text { Среднее } \\
\text { значение } \\
\text { Mean value }\end{array}$ & $\begin{array}{c}\text { Стандартное } \\
\text { отклонение } \\
\text { Standard } \\
\text { deviation }\end{array}$ \\
\hline $\begin{array}{l}\sigma_{c i}, \text { прочность на одноосное сжатие } \\
\text { oбразца горной породы } \\
\text { в ненарушенном состоянии } \\
\text { intact uniaxial compressive strength }\end{array}$ & $45 \mathrm{M \Pi а} / \mathrm{MPa}$ & $15 \mathrm{M \Pi а} / \mathrm{MPa}$ \\
\hline $\begin{array}{l}\text { GSI, геологический индекс прочности } \\
\text { Geological Strength Index }\end{array}$ & 55 & 10 \\
\hline \begin{tabular}{|l|}
$m_{i}$, параметр ненарушенной породы \\
material constant for the intact rock
\end{tabular} & 20 & 5 \\
\hline $\begin{array}{l}\text {, коэффициент нарушения } \\
\text { disturbance factor }\end{array}$ & 0,8 & 0,1 \\
\hline $\begin{array}{l}\sigma_{\text {верг }}, \text { вертикальные напряжения } \\
\text { vertical stresses }\end{array}$ & 13 & 2 \\
\hline $\begin{array}{l}\sigma_{\text {шир }}, \text { горизонтальные широтные } \\
\text { напряжения } \\
\text { horizontal latitudinal stresses }\end{array}$ & 16 & 2 \\
\hline \begin{tabular}{|l}
$\sigma_{\text {мер }}$, горизонтальные \\
меридиональные напряжения \\
horizontal longitudinal stresses
\end{tabular} & 18 & 2 \\
\hline
\end{tabular}

Исследования включали две стадии: на первом этапе анализировалось изменение напряженно-деформированного состояния окружающего массива после образования одиночной камеры, на втором этапе - после формирования двух камер. Кроме того, моделирование выполнялось при различных геометрических параметрах выработок - камер и целиков [26].

\section{Результаты и обсуждение}

В результате численного моделирования определяется изменение напряженно-деформированного состояния окружающего массива, вызванное образованием выработанного пространства, на основании чего оцениваются условия его устойчивости, а именно - коэффициент устойчивости (Strength Factor) и распределение трещин (Yielded Elements) [27].

Значение коэффициента Strength Factor, равное или превышающее 1,0 , соответствует устойчивому состоянию выработки, меньшие значения высокой вероятности обрушения массива. На основании оценки данного параметра были установлены оптимальные размеры выработок, обеспечивающие их устойчивость в процессе разработки (табл. 2). Кроме того, придание кровле камер арочной формы позволяет снизить величину действующих на ее контуре напряжений [26, 28].

Таблица 2. Оптимальные параметры камер и целиков

Table 2. Optimal parameters of chambers and pillars

\begin{tabular}{|c|c|c|}
\hline & $\begin{array}{l}\text { Вкрест простирания } \\
\text { Across strike }\end{array}$ & $\begin{array}{l}\text { По простиранию } \\
\text { Along strike }\end{array}$ \\
\hline $\begin{array}{l}\text { Высота камеры } \\
\text { Chamber height }\end{array}$ & \multicolumn{2}{|c|}{$\begin{array}{c}\text { Не более } 35 \mathrm{~m} \\
\text { Not more than } 35 \mathrm{~m}\end{array}$} \\
\hline $\begin{array}{l}\text { Ширина камеры } \\
\text { Chamber width }\end{array}$ & $\begin{array}{c}\text { Не более } 17 \mathrm{~m} \\
\text { Not more than } 17 \mathrm{~m}\end{array}$ & $\begin{array}{c}\text { Не более } 22 \mathrm{M} \\
\text { Not more than } 22 \mathrm{~m}\end{array}$ \\
\hline $\begin{array}{l}\text { Межкамерный целик } \\
\text { Room pillar }\end{array}$ & $\begin{array}{c}\text { Hе менее } 30 \mathrm{~m} \\
\text { Not less than } 30 \mathrm{~m}\end{array}$ & - \\
\hline $\begin{array}{l}\text { Межблочный целик } \\
\text { Block pillar }\end{array}$ & - & $\begin{array}{c}\text { Не менее } 30 \mathrm{~m} \\
\text { Not less than } 30 \mathrm{~m}\end{array}$ \\
\hline $\begin{array}{l}\text { Форма кровли } \\
\text { Roof form }\end{array}$ & \multicolumn{2}{|c|}{$\begin{array}{l}\text { Aрочная } \\
\text { Arched }\end{array}$} \\
\hline
\end{tabular}

Результаты моделирования с заданными оптимальными параметрами камер и целиков представлены на рис. 2-4. Необходимо отметить, что ввиду схожести граничных условий, а именно - близости значений действующих широтных и меридиональных напряжений и пространственного расположения выработок относительно них, вычисленные размеры устойчивых камер вкрест и по простиранию близки между собой. Следовательно, и результаты компьютерного моделирования, полученные для продольных и поперечных разрезов выработок, практически аналогичны.

На рис. 2 показано определенное по результатам моделирования распределение коэффициента устойчивости массива вокруг выработанного пространства вкрест простирания, а также картина распределения возможных трещин сдвига и растяжения (Shear and Tension joints).

При анализе рис. 2 видно, что по данным моделирования значение коэффициента устойчивости вблизи выработанного пространства составляет не менее 1,0 , что соответствует устойчивому состоянию массива. Картина распределения потенциальных трещин свидетельствует о возможности ло- 


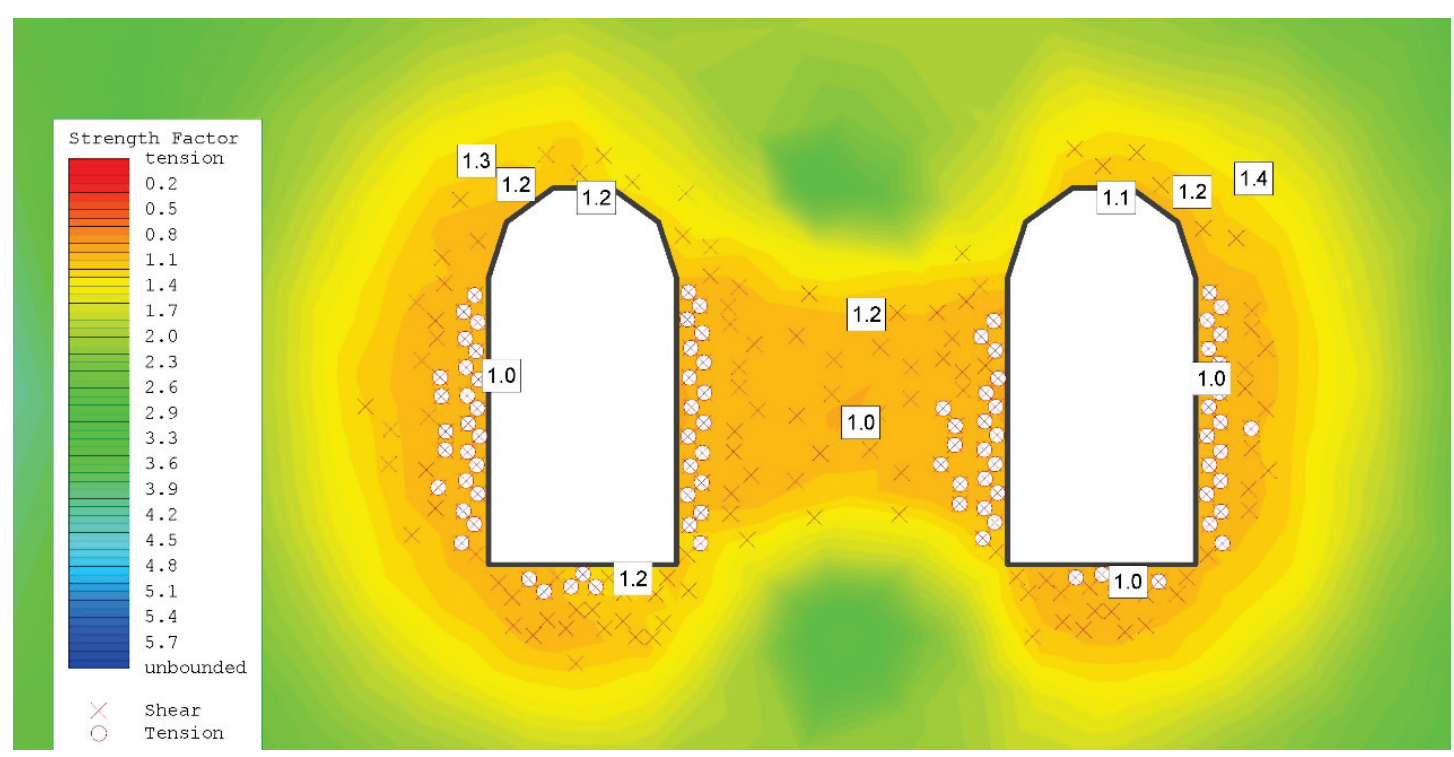

Рис. 2. Распределение коэффициента устойчивости массива (разрез вкрест простирания)

Fig. 2. Distribution of the rock mass safety factor (section across strike)

кального нарушения стенок камер, но при этом устойчивость кровли сохраняется.

На рис. 3 представлены величины и направления смещений окружающего массива и контуров выработок, вызванные изменением напряженнодеформированного состояния после образования двух камер, определенные в результате моделирования. Прогнозируемые смещения породных стенок направлены к центрам камер - явление, известное как конвергениия [29-31]. Их величины на разрезе вкрест простирания по расчетным данным могут достигать значения $11 \mathrm{~cm}$ во внешних стенках выработки и около 6 см в ее кровле.

На рис. 4 представлены результаты вероятностного анализа обрушения окружающего масси- ва с учетом изменения граничных условий (табл. 1). Темные области свидетельствуют о том, что обрушение окружающего массива произойдет при любом значении граничных условий из заданного интервала. Более светлые области свидетельствуют о наименее вероятной возможности обрушения массива.

При анализе рис. 4 установлено, что зоны наибольшей вероятности обрушения массива сконцентрированы в стенках и почве камер, возможность обрушения кровли камер маловероятна. Глубина нарушенной зоны по данным моделирования составляет около 6 м. Вероятность устойчивости целика оценивается как удовлетворительная для заданного диапазона значений граничных условий.

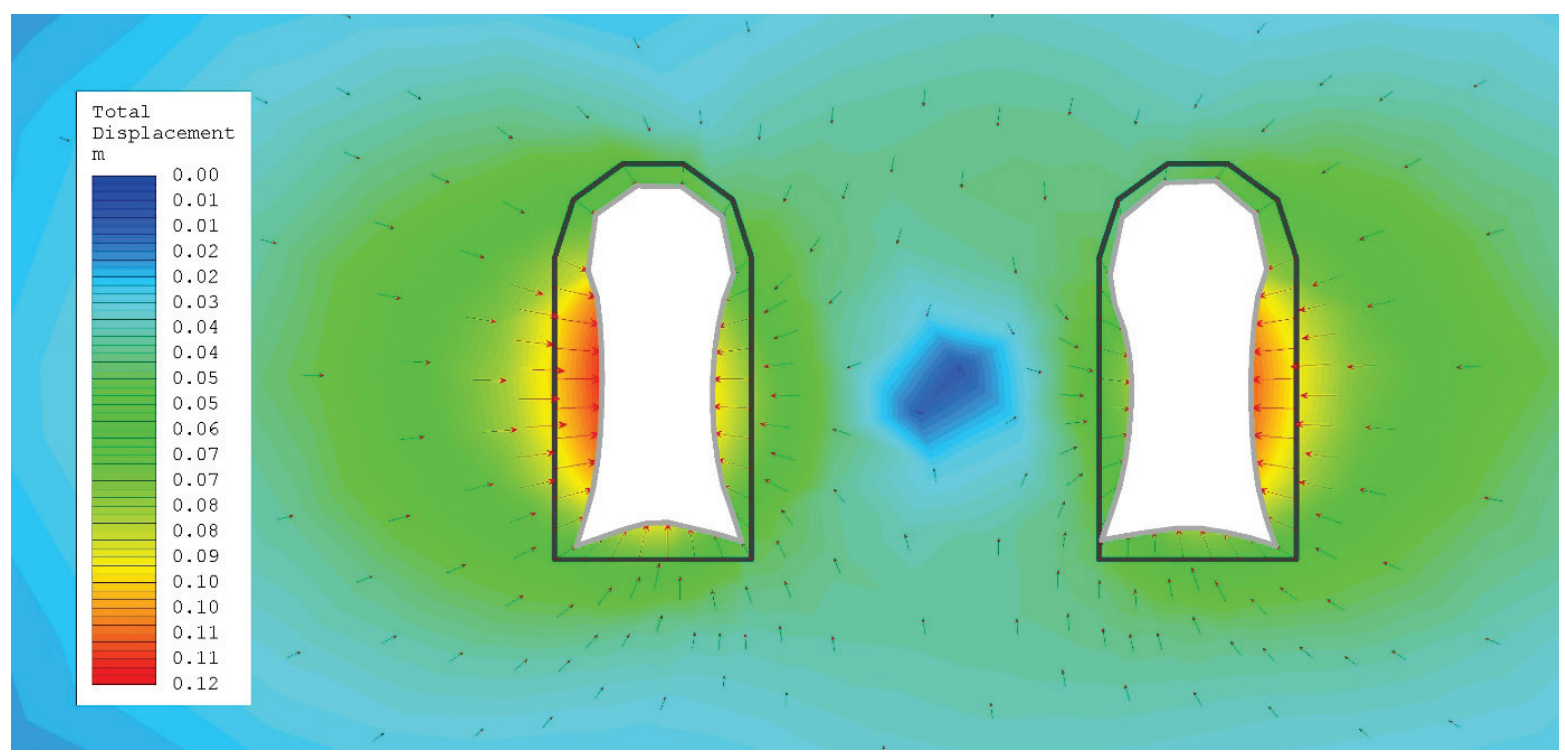

Pис. 3. Смещения породных стенок выработок и окружающего массива (разрез вкрест простирания)

Fig. 3. Displacements of the excavations' checks and the surrounding rock mass (section across strike) 


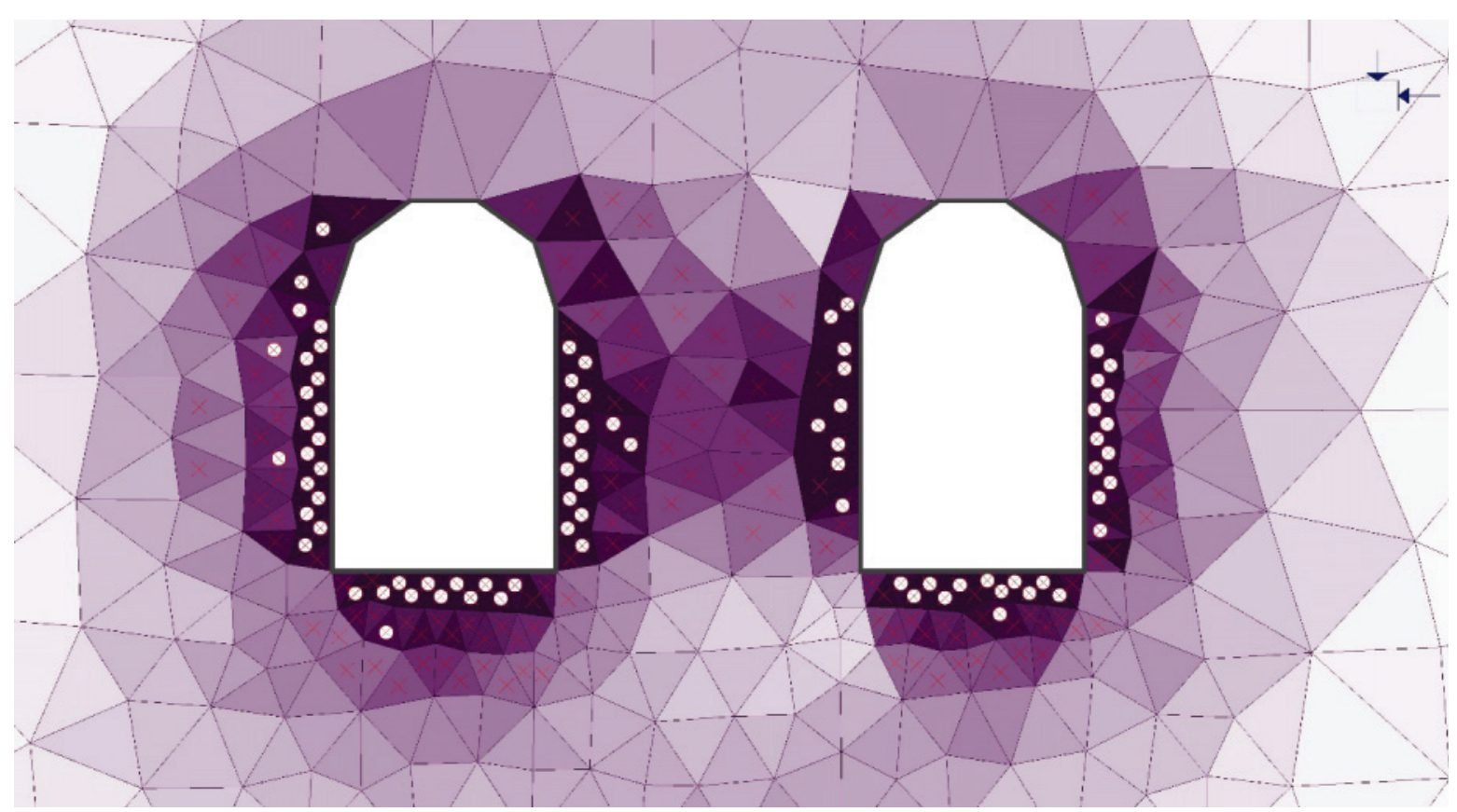

Рис. 4. Зоны распределения вероятности разрушения массива в заданных интервалах граничных условий (разрез по простиранию)

Fig. 4. Zones of distribution of the rock mass destruction probability within the variation intervals of boundary conditions (section along strike)

\section{Выводы}

Рекомендованная для применения на ш. «Соколовская» двухстадийная технология отработки очистных рудных блоков снижает риск проникновения ПГМ в выработки, обеспечивая более безопасное и эффективное ведение горных работ, чем принятая в настоящее время на руднике система этажного принудительного обрушения со сплошной выемкой руды, а также повышает полноту и качество выемки руды. Однако полностью ее преимущества реализуются при условии сохранения устойчивости кровли компенсационных камер.

Выполненное методом конечных элементов многовариантное численное моделирование влияния очистных выработок на массив позволило определить оптимальные геометрические параметры камер и целиков, обеспечивающие устойчивость окружающего массива в процессе разработки. Рекомендуемая арочная форма кровли камер

\section{СПИСОК ЛИТЕРАТУРЫ}

1. Урдубаев Р.А., Верин С.В., Шихаметов Р.В. Подземные горные работы в АО «ССГПО» // Горный журнал. - 2014. - № 6. C. $32-37$.

2. Тюпин В.Н. Установление динамически устойчивых размеров обнажений трещиноватого напряженного горного массива при камерных вариантах систем разработки / Вестник Забайкальского государственного университета. - 2016. - Т. 22. - № 6. C. 31-39.

3. Куранов А.Д., Сидоров Д.В., Сучилин А.В. Метод определения безопасных параметров междукамерных целиков на рудниках ЗАО «Эльконский ГМК» // Известия Тульского государственного университета. Науки о Земле. - 2013. - № 1. C. $115-119$. обеспечивает устойчивость потолочины, минимизируя вероятность ее самообрушения и выхода ПГМ в выработанное пространство.

Применение программного комплекса Rocscienсе RS2 позволило учесть большое количество факторов, влияющих на напряженно-деформированное состояние массива, а также проанализировать изменение граничных условий модели и оценить вероятность обрушения. Реализованный в программном комплексе критерий прочности Хоека-Брауна учитывает нелинейное деформирование скальных грунтов, а также структурные особенности массива и степень техногенного воздействия на него.

С целью проверки результатов теоретических исследований на руднике планируется создание опытно-промышленного участка. Результаты натурных исследований позволят сделать окончательный вывод об эффективности предложенной технологии.

4. Niculae R.R. The surface's stability analysis with finite element method under the coal mining at e.m. Livezeni // Journal of Young Scientist. - 2013. - V. I. - P. 69-74.

5. Radouane N., Boukelloul M., Fredj M. Stability Analysis of Underground Mining and their Application on the Mine Chaabte El Hamra, Algeria // Procedia Earth and Planetary Science. 2015. - V. 15. - P. 237-243. DOI: 10.1016/j.proeps.2015.08.058

6. Shabanimashcool M., Li C.C. A numerical study of stress changes in barrier pillars and a border area in a longwall coal mine // Int. J. Coal Geol. - 2013. - V. 106. - P. 39-47. DOI: 10.1016/j.coal.2012.12.008

7. Numerical investigation of coal pillar failure under simultaneous static and dynamic loading / S. Wang, S. Hao, Y. Chen, J. Bai, X. Wang, Y. Xu // Int. J. Rock Mech. Min. Sci. - 2016. - V. 84. P. 59-68. DOI: 10.1016/j.ijrmms.2016.01.017 
8. Авдеев А.Н., Давиденко А.А., Сосновский Л.И. Обоснование параметров устойчивых междукамерных целиков и обнажений кровли камер на Тыретском руднике // Вестник Иркутского государственного технического университета. - 2014. № $12 .-$ C. $66-71$.

9. Подопригора В.Е. Обоснование рациональных параметров подэтажно-камерной системы разработки с применением метода конечных элементов // Горный информационно-аналитический бюллетень. - 2005. - № 5. - С. 216-219.

10. Литвиненко В.С., Богуславский Э.И., Коржавых П.В. Физическое и математическое моделирование технологических параметров этажно-камерной системы разработки нижнего горизонта рудника им. Губкина // Записки горного института. 2012. - T. 195. - C. 115-119.

11. Черепов А.А., Ширяев С.Н., Кулак В.Ю. Исследование распределения напряжений и деформаций геомассива при камерностолбовой системе разработки мощного пологого угольного пласта // Горный информационно-аналитический бюллетень. - 2017. - № 9. - С. 170-178. DOI: 10.25018/ 0236-1493-2017-9-0-170-178

12. Петров А.Н., Слепцов В.И., Акимов Д.Д. Оценка устойчивости камер в условиях месторождения «Мир» // Горный информационно-аналитический бюллетень. - 2014. - № 9. C. $389-393$.

13. Nomikos P.P., Sofianos A.I. An analytical probability distribution for the factor of safety in underground rock mechanics // Int. J. Rock Mech. Min. Sci. - 2011. - V. 48. - Iss. 4. P. 597-605. DOI: 10.1016/j.ijrmms.2011.02.015

14. Yang H., Kim W., Ali M. Performance of pillar design in underground stone mines that include discontinuities / Geosystem Engineering. - 2012. - V. 15. - Iss. 3. - P. 187-194. DOI: $10.1080 / 12269328.2012 .704160$

15. Gaede 0., Schrank C., Canbulat I., Karrech A. A strain-based failure criterion for pillar stability analysis // AusRock 2014: Proceedings of Third Australasian Ground Control in Mining Conference. - Sydney: The Australasian Institute of Mining and Metallurgy, 2014. - P. 393-398.

16. Huang Z., Dai X., Dong L. Buckling failures of reserved thin pillars under the combined action of in-plane and lateral hydrostatic compressive forces // Comput. Geotech. - 2017. - V. 87. P. 128-138. DOI: 10.1016/j.compgeo.2017.02.013

17. Research on reasonable size of large coal pillar between panels at mining face with soft surrounding rock / W. Zhang, X. Kong, T. Kang, G. Zhao // Min. Res. Dev. - 2013. - V. 33. - P. 14-17.

18. Determining the reasonable width of narrow pillar of entry in gob entry driving in the large pillar / K. Zhang, Y. Jiang, Z. Zhang, Y. Zhang, X. Pang, X. Zeng // J. Min. Saf. Eng. - 2014. V. 31 . - P. 255-262.

19. Rocscience RS2. URL: https://www.rocscience.com/softwa$\mathrm{re} / \mathrm{rs} 2$ (дата обращения 07.08.2018).

20. Численное моделирование напряженно-деформированного состояния массива в окрестности очистного пространства в программе «Phase 2» / П.С. Шпаков, В.Н. Долгоносов, А.А. Наги- бин, Е.В. Кайгородова // Горный информационно-аналитический бюллетень, - 2015. - № 9. - С. 59-66.

21. Панжин А.А., Панжина Н.А. Природное и техногенно измененное напряженно-деформированное состояние породного массива на ССГПО // Маркшейдерия и недропользование. 2014. - № 5 (73). - C. 44-51.

22. Особенности напряженного состояния горного массива Соколовского железорудного месторождения / А.Е. Балек, А.А. Панжин, Ю.П. Коновалова, Д.Е. Мельник // Инновационные геотехнологии при разработке рудных и нерудных месторожждений: сб. докладов VII Международной научно-технической конференции. - Екатеринбург, 11 апреля 2018. Екатеринбург: УГГУ, 2018. - С. 256-264.

23. Hoek E., Wood D., Shah S. A modified Hoek-Brown failure criterion for jointed rock masses // Eurock 1992: Proceedings of the International ISRM Symposium on Rock Characterization. - London, 1992. - P. 209-213.

24. Hoek E., Carranza-Torres C., Corkum B. Hoek-Brown failure criterion - 2002 Edition // NARMS-TAC 2002: Proceedings of the Conference. - Toronto, 2002. - P. 267-273.

25. Сас И.Е., Бершов А.В. Об особенностях модели поведения скального грунта Хоека - Брауна и задании ее исходных параметров // Инженерные изыскания. - 2015. - № 13. - С. 42-47.

26. Steady analysis of gob-side entry retaining formed by roof fracturing and control techniques by optimizing mine pressure / Y. Gao, Z. Guo, J. Yang, J. Wang, Y. Wang // J. China Coal Soc. 2017. - V. 42. - P. 1672-1681.

27. Sepehri M., Apel D., Liu W. Stope stability assessment and effect of horizontal to vertical stress ratio on the yielding and relaxation zones around underground open stopes using empirical and finite element methods // Arch. Min. Sci. - 2017. - V. 62. № 3. - P. 653-669. DOI: 10.1515/amsc-2017-0047

28. Павлов С.П., Крысько В.А., Бодягина К.С. К вопросу об оптимизации формы геологических выработок и топологии их укрепления // Известия Томского политехнического университета. Инжиниринг георесурсов. - 2017. - Т. 328. - № 1. C. $6-12$.

29. Харисов Т.Ф. Исследования конвергенции породных стенок ствола в условиях запредельного состояния призабойного массива // Известия высших учебных заведений. Горный журнал. - 2017. - № 5. - С. 46-51.

30. Харисов Т.Ф., Князев Д.Ю. Закономерности деформирования породных стенок ствола в процессе продвижения забоя в условиях запредельного напряженно-деформированного состояния массива // Проблемы недропользования. - 2017. - № 1 (12). C. $96-101$. DOI: $10.18454 / 2313-1586.2017 .01 .096$

31. Харисов Т.Ф., Антонов В.А. Исследование деформации горных пород в процессе проходки вертикального ствола // Горный информационно-аналитический бюллетень. - 2015. № 3. - C. 146-150.

Поступила 13.10.2018 г.

\section{Информация об авторах}

Харисов Т.Ф., кандидат технических наук, старший научный сотрудник лаборатории геомеханики подземных сооружений Института горного дела УрО РАН.

Харисова О.Д., научный сотрудник лаборатории сдвижения горных пород Института горного дела УрО РАН. 


\title{
GEOMECHANICAL SUBSTANTIATION OF THE PARAMETERS OF STABLE CHAMBERS AND PILLARS IN COMPLEX MINING AND GEOLOGICAL CONDITIONS
}

\author{
Timur F. Kharisov', \\ timur-ne@mail.ru \\ Olga D. Kharisova', \\ OlgaZheltysheva@gmail.com \\ 1 Institute of Mining of Ural Branch of RAS, \\ 58, Mamin-Sibiryak street, Ekaterinburg, 620075, Russia.
}

The relevance of the research is caused by the necessity of ensuring safety at the Sokolovski underground mine, as well as improving the completeness and quality of excavation of resources in complex mining and geological conditions - in the presence of a covering layer of watered loose sediments.

The aim of the research is to determine the optimal parameters of stable chambers and pillars to prevent rock collapse and penetration of sandy-argillaceous deposits into underground excavations.

The object: the rock mass in the Northern area of Sokolovskoe deposit.

Methods. Multivariate numerical modeling with the finite element method in a two-dimensional approach was performed in the Rocscience RS2 software, which allowed taking into account a large number of factors affecting the state of the massif. The calculations included not only the physical and mechanical properties of rocks and the acting stresses, but also the structural characteristics of the rock mass, as well as the level of technogenic impact. As a model of the massif behavior, the Hoech-Brown model was used, which distinctive advantage is nonlinearity. Since the real rock mass is characterized by heterogeneity of the strength properties and the stressstrain state, the probabilistic analysis provided in the Rocscience software was implemented, taking into account the variations of the boundary conditions within the established intervals for the created model.

As a result of numerical simulation, a change of the stress-strain state of the massif was determined, on the basis of which the safety factor of the surrounding rock mass was calculated, as well as the magnitudes and directions of its displacements, and also zones of distribution of the massif destruction probability within the given intervals of boundary conditions were established. The parameters of the chambers and pillars which ensure the overall stability and minimize the possibility of breaking mud water into the workings were determined.

Conclusions. Maintaining the stability of the roof of the underground chambers while stopping ore blocks at the Sokolovskaya mine will enable to reduce the risk of sandy-argillaceous deposits penetration into the underground openings, ensuring safe and efficient mining, and also to improve the completeness and quality of resources excavation. The multivariate numerical modelling of the influence of mine openings on the rock mass made by the finite element method allowed determining the optimal geometric parameters of chambers and pillars that ensure the stability of the surrounding massif. Application of the Rocscience RS2 software due to accounting a large number of factors affecting the state of the massif significantly improves the reliability of rock mass stability assessment.

\section{Key words:}

Underground mining, parameters of chambers and pillars, stability of excavations, rock collapse, stress-strain state, Hoek-Brown model, finite element method, numerical simulation, Rocscience RS2, convergence of excavations.

\section{REFERENCES}

1. Urdubaev R.A., Verin S.V., Shikhametov R.V. Underground mine operations in «Sokolovsko-Sarbaiskoe mining and concentration production association» JSC. Mining journal, 2014, no. 6, pp. 32-37. In Rus.

2. Tyupin V.N. Establishment of dynamically steady sizes of exposures of the jointed intense massif at chamber options of systems of development. Bulletin of the Transbaikal State University, 2016, vol. 22, no. 6, pp. 31-39. In Rus.

3. Kuranov A.D., Sidorov D.V., Suchilin A.V. Method for determining safety parameters of room pillars at uranium ore mines of Elkon ore district. Proceedings of the Tula State University. Earth Sciences, 2013, no. 1, pp. 115-119. In Rus.

4. Niculae R.R. The surface's stability analysis with finite element method under the coal mining at e.m. Livezeni. Journal of Young Scientist, 2013, vol. I, pp. 69-74.

5. Radouane N., Boukelloul M., Fredj M. Stability Analysis of Underground Mining and their Application on the Mine Chaabte El Hamra, Algeria. Procedia Earth and Planetary Science, 2015, vol. 15, pp. 237-243. DOI: 10.1016/j.proeps.2015.08.058

6. Shabanimashcool M., Li C.C. A numerical study of stress changes in barrier pillars and a border area in a longwall coal mine. Int. J.Coal Geol., 2013, vol. 106, pp. 39-47. DOI: 10.1016/j.coal.2012.12.008
7. Wang S., Hao S., Chen Y., Bai. J., Wang X., Xu Y. Numerical investigation of coal pillar failure under simultaneous static and dynamic loading. Int. J. Rock Mech. Min. Sci., 2016, vol. 84, pp. 59-68. DOI: $10.1016 /$ j.ijrmms.2016.01.017

8. Avdeev A.N., Davidenko A.A., Sosnovskiy L.I. Parameter justification of sustainable intervening pillars and roof exposures at Tyret mine. Bulletin of Irkutsk State Technical University, 2014, no. 12, pp. 66-71. In Rus.

9. Podoprigora V.E. Obosnovanie ratsionalnykh parametrov podetazhno-kamernoy sistemy razrabotki s primeneniem metoda konechnykh elementov [Substantiation of rational parameters of the sublevel-chamber development system using the finite element method]. Gorny informatsionno-analiticheskiy byulleten, 2005, no. 5 , pp. 216-219.

10. Litvinenko V.S., Boguslavskiy E.I., Korhzavykh P.V. Physical and mathematical modelling of level-chamber method operational parameters at the bottom level of Gubkin mine. Journal of $\mathrm{Mi}$ ning Institute, 2012, vol. 195, pp. 115-119. In Rus.

11. Cherepov A.A., Shiryaev S.N., Kulak V.Yu. Stress and strain distribution in geomass under room-and-pillar mining of a thick gently dipping coal bed. Mining informational and analytical bulletin, 2017, no. 9, pp. 170-178. In Rus. D0I: 10.25018/ 0236-1493-2017-9-0-170-178 
12. Petrov A.N., Sleptsov V.I., Akimov D.D. Estimation of stope stability at the Mir deposit. Mining informational and analytical bulletin, 2014, no. 9, pp. 389-393. In Rus.

13. Nomikos P.P., Sofianos A.I. An analytical probability distribution for the factor of safety in underground rock mechanics. Int. J. Rock Mech. Min. Sci., 2011, vol. 48, Iss. 4, pp. 597-605. D0I: 10.1016/j.ijrmms.2011.02.015

14. Yang H., Kim W., Ali M. Performance of pillar design in underground stone mines that include discontinuities. Geosystem Engineering, 2012, vol. 15, Iss. 3, pp. 187-194. D0I: $10.1080 / 12269328.2012 .704160$

15. Gaede 0., Schrank C., Canbulat I., Karrech A. A strain-based failure criterion for pillar stability analysis. AusRock 2014. Proc. of Third Australasian Ground Control in Mining Conference. Sydney, The Australasian Institute of Mining and Metallurgy, 2014. pp. 393-398.

16. Huang Z., Dai X., Dong L. Buckling failures of reserved thin pillars under the combined action of in-plane and lateral hydrostatic compressive forces. Comput. Geotech., 2017, vol. 87, pp. 128-138. DOI: 10.1016/j.compgeo.2017.02.013

17. Zhang W., Kong X., Kang T., Zhao G. Research on reasonable size of large coal pillar between panels at mining face with soft surrounding rock. Min. Res. Deu., 2013, vol. 33, pp. 14-17.

18. Zhang K., Jiang Y., Zhang Z., Zhang Y., Pang X., Zeng X. Determining the reasonable width of narrow pillar of entry in gob entry driving in the large pillar. J. Min. Saf. Eng., 2014, vol. 31, pp. $255-262$.

19. Rocscience RS2. Available at: https://www.rocscience.com/ software/rs2 (accessed 1 August 2018).

20. Shpakov P.S., Dolgonosov V.N., Nagibin A.A., Kaygorodova E.V. Modeling stress-strain state of rocks around stoping zone in Phase 2 program. Mining informational and analytical bulletin, 2015, no. 9, pp. 59-66. In Rus.

21. Pangin A.A., Pangina N.A. Native and technogenic influenced stressedly deformed rock massif state at «SSGPO» public company. Mine Surveying and Subsurface Exploitation, 2014, no. 5 (73), pp. 44-51. In Rus.

22. Balek A.E., Panzhin A.A., Konovalova Yu.P., Melnik D.E. Osobennosti napryazhennogo sostoyaniya gornogo massiva Sokolovskogo zhelezorudnogo mestorozhdeniyz [Features of the stressed state of the mountain massif of Sokolovsky iron-solid deposit]. Innovatsionnye geotekhnologii pri razrabotke rudnykh i nerudnykh mestorozhdeny. Sbornik dokladov VII Mezhdunarodnoy nauchnotekhnicheskoy konferentsii [Innovative geotechnologies in the development of ore and non-ore deposits. Proc. of Seventh International scientific and technical conference]. Ekaterinburg, Ural State Mining University, 2018. pp. 256-264.

23. Hoek E., Wood D., Shah S. A modified Hoek-Brown failure criterion for jointed rock masses. Eurock 1992. Proc. of the International ISRM Symposium on Rock Characterization. London, 1992. pp. 209-213.

24. Hoek E., Carranza-Torres C., Corkum B. Hoek-Brown failure criterion-2002 Edition. NARMS-TAC 2002. Proc. of the Conference. Toronto, 2002. pp. 267-273.

25. Sas I.E., Bershov A.V. On features of the Hoek-Brown rock behavior model and determining its initial parameters. Engineering Survey, 2015, no. 13, pp. 42-47. In Rus.

26. Gao Y., Guo Z., Yang J., Wang J., Wang Y. Steady analysis of gob-side entry retaining formed by roof fracturing and control techniques by optimizing mine pressure. J.China Coal Soc., 2017, vol. 42, pp. 1672-1681.

27. Sepehri M., Apel D., Liu W. Stope stability assessment and effect of horizontal to vertical stress ratio on the yielding and relaxation zones around underground open stopes using empirical and finite element methods. Arch. Min. Sci., 2017, vol. 62, no. 3, pp. 653-669. DOI: $10.1515 / \mathrm{amsc}-2017-0047$

28. Pavlov S.P., Krysko V.A., Bodyagina X.S. On the issue of optimizing the shape of geological excavations and topology of their strengthening. Bulletin of the Tomsk Polytechnic University. Geo Assets Engineering, 2017, vol. 328, no. 1, pp. 6-12. In Rus.

29. Kharisov T.F. Mine shaft rock walls convergence investigations in the conditions of the out-of-limit state of the borehole massif. News of the Higher Institutions. Mining Journal, 2017, no. 5, pp. 46-51. In Rus.

30. Kharisov T.F., Knyazev D.Yu. The regularities of deforming the shaft's rock walls during the process of face advancing in the conditions of rock mass limit-exceeding stressed- deformed state. Subsurface Exploitation Issues, 2017, no. 1 (12), pp. 96-101. In Rus. DOI: 10.18454/2313-1586.2017.01.096

31. Kharisov T.F., Antonov V.A. Study of the deformation of rocks in the process of vertical shaft sinking. Mining informational and analytical bulletin, 2015, no. 3, pp. 146-150. In Rus.

Received: 13 October 2018.

\section{Information about the authors}

Timur F. Kharisov, cand. Sc., senior researcher, Institute of Mining of Ural Branch of RAS.

Olga D. Kharisova, researcher, Institute of Mining of Ural Branch of RAS. 